\title{
A biografia e sua instrumentalidade educativa
}

\author{
Jonaedson Carino
}

\begin{abstract}
RESUMO: O presente artigo trata do gênero biografia, associando-o à educação por meio de um pressuposto: o de que as construções biográficas contêm uma instrumentalidade educativa, podendo ser apreciadas no contexto de uma pedagogia do exemplo. Parte integrante dos estudos de seu autor que culminaram em tese de doutoramento na UFRJ, o trabalho contém uma síntese histórica da trajetória do gênero biográfico segundo periodização proposta por Madelénat, além de apresentar uma fundamentação teórica de análise das biografias apoiada, especialmente, em Wilhelm Dilthey. $\mathrm{O}$ artigo pretende, ainda, destacar a pertinência e a relevância do estudo das construções biográficas, notadamente em sua relação com a educação.
\end{abstract}

Palavras-chave: Biografia, exemplaridade, vida, educação

\section{Introdução}

Biografias fascinam. Raros são os que se quedam indiferentes diante das vicissitudes de uma vida. Poucos conseguem manter-se alheios a embates, fracassos e vitórias vividos nas existências alheias. Mesmo os detratores do gênero traem seu aparente desinteresse: geralmente sua crítica dirige-se menos aos males intrínsecos aos perfis biográficos do que a seu papel de instrumento de um "odioso individualismo".

\footnotetext{
'Professor Adjunto na Faculdade de Educação da UERJ e no Mestrado em Educação da Universidade Católica de Petrópolis.
} 
Quanto ao sucesso das narrativas de vida, é inegável, posto que se mantêm em evidência há mais de 2.000 anos. Desde os tempos do neoplatônico Damaskios, no século $V$ a.C., a quem se atribui a cunhagem da palavra biografia (de bios, vida e gráphein, escrever, descrever, desenhar), a narrativa de trajetórias individuais permanece em destaque, suscitando interesse, quaisquer que sejam sua forma ou as intenções que motivam sua elaboração.

Por que fascinam as biografias? Antes, talvez se devesse perguntar: por que fascinam as trajetórias individuais? A fascinação não advém da singularidade? Provavelmente. Cada vida é una, indivisível, irrepetível, intransmissível. ${ }^{1} \mathrm{O}$ fascínio pelo Uno é ancestral, remonta às origens da própria Filosofia. O Uno contraposto ao Múltiplo gerou elucubrações situadas na base de todos os esforços metafísicos. Desde os filósofos denominados pré-socráticos, essa mística do Uno foi transformada em motivo de reflexão acerca da natureza do universo: o Uno seria a propriedade de tudo que é, do universo como Unidade. Opondo-se ao Múltiplo, que é ilusão e opinião, o Uno seria verdade, simplicidade, uniformidade e identidade pura.

Biografar é, pois, descrever a trajetória única de um ser único, original e irrepetível; ${ }^{2}$ é traçar-lhe a identidade refletida em atos e palavras; é cunhar-lhe a vida pelo testemunho de outrem; é interpretálo, reconstruí-lo, quase sempre revivê-lo. O mistério do singular é, também, fortíssimo como elemento constitutivo do imaginário cultural de qualquer sociedade ou mesmo civilização. Deus, suprema síntese, não seria $O$ Uno, O Singular? Mas a fascinação biográfica tem um aspecto muito interessante, ao qual se pretende dedicar estas reflexões. Trata-se do que se poderia denominar sua instrumentalidade educativa.

Não se biografa em vão. Biografa-se com finalidades precisas: exaltar, criticar, demolir, descobrir, renegar, apologizar, reabilitar, santificar, dessacralizar. Tais finalidades e intenções fazem com que retratar vidas, experiências singulares, trajetórias individuais transforme-se, intencionalmente ou não, numa pedagogia do exemplo. A força educativa de um relato biográfico é inegável.

Há outro aspecto tanto mais significativo quanto intrigante, afim das presentes reflexões. Seria de esperar que, no interior do relato biográfico, as experiências formativas adquirissem relevância. Curiosamente, não é isso que se observa. Compulsando-se biografias, vê-se que a 
formação sistemática dos biografados é relegada a segundo plano. Agese, regra geral, como se os biografados fossem seres auto-suficientes, autodidatas empedernidos, em cuja genialidade intrínseca se situaria a fonte de seu futuro sucesso (que é traduzido como fracasso moral, no caso dos exemplos "negativos"). Somente o exame do gênero e de seus exemplos concretos poderá fornecer explicação para esse aparente descaso dos biógrafos em relação à fase de educação na vida de seus biografados.

Estas reflexões postulam, portanto, a importância do estudo da biografia como veículo educativo. Elas integram estudo mais amplo constitutivo de tese de doutorado defendida pelo autor no programa de pós-graduação em educação da Universidade Federal do Rio de Janeiro, no eixo temático Pensamento educacional brasileiro. ${ }^{3}$

Não se encontram na literatura educacional brasileira estudos sobre as biografias do ponto de vista ora proposto. Há um número grande de biógrafos para uma multidão de biografados. Existem competentes análises de vidas e de obras, sobretudo no campo da literatura. Encontram-se vários estudos exemplares, verdadeiros marcos bibliográficos sobre o tema. ${ }^{4}$ Porém, o aspecto da exemplaridade educativa nunca foi enfatizado. Biógrafos raramente assumem seu papel de "instrumentos" da educação, ou pelo menos não apresentam esse papel de forma consciente e lúcida. Embora as apologias proliferem, seus autores preferem tentar esconder-se (sem êxito) por detrás de uma pretensa neutralidade. Quando a admiração pelos biografados é forte a ponto de tornar-se incontrolável, os biógrafos preferem renunciar a qualquer distanciamento crítico e deixam-se levar, satisfeitos e gozosos, pelas ondas arrebatadoras de sua paixão, tornando-se cegos (como qualquer apaixonado) e chegando muitas vezes a naufragar no ridículo. Em verdade, o que fazem são "hagiografias", cuidando, eles mesmos, de canonizar seus biografados.

A questão proposta - estabelecer seu papel educativo - exigirá, obviamente, a análise empírica das biografias. Mas, antes disso, é necessário estabelecer parâmetros ou mesmo um modelo de análise. Essa é a tarefa que foi levada a efeito na tese já referida, desenvolvida em três campos de estudo: a) um estudo histórico do gênero biografia, com suas transformações ao longo do tempo; b) o exame de problemas contidos na construção biográfica, especialmente daqueles que sirvam para a aproximação com o aspecto educativo das biografias; e c) a tentativa de construção de parâ- 
metros ou de um modelo de análise que permita o exame das biografias em sua instrumentalidade educativa.

O presente artigo levanta algumas questões e alguns problemas, bem como faz a introdução de textos que serviram de fundamentação teórica para a análise empreendida na tese já mencionada.

\title{
Considerações de ordem histórica
}

A gênese da forma de relato denominada "biografia", situada na Antigüidade, está bem configurada. Conforme acentua Dilthey (1945, p. 317), representa um marco nessa forma de expressão:

\begin{abstract}
O conhecimento da natureza e o valor da individualidade foram se desenrolando pouco a pouco na humanidade européia. Sócrates é o primeiro a tomar consciência do processo moral dentro de si mesmo, o que torna possível o desenvolvimento da pessoa unitária. O "conhece-te a ti mesmo" orienta-se, em primeiro lugar, ao uniforme da natureza humana, porém, desta, que nele oferecia validez universal e que elevou à luz do saber, teria de separar-se o poderoso, o insondável, que designava como "demônio", e que, sem dúvida, pertencia à profundidade da subjetividade. A partir de então, Sócrates converteu-se, para seus discípulos, para os estóicos, Montaigne, etc., no tipo da reversão do pensamento às profundidades da pessoa.
\end{abstract}

Jaeger (1979, p. 498) acentuara esse caminho na direção da interioridade, que vai singularizar cada homem: "A experiência da alma como fonte dos supremos valores humanos deu à existência aquele jeito de interioridade, característico dos últimos tempos da Antigüidade. A virtude e a felicidade deslocaram-se, assim, para o interior do Homem."

A própria questão da vida, numa dimensão mais ampla além do nível biológico, e a questão de seu sentido são tratadas pelos gregos, tendo Sócrates como o exemplo supremo:

Foi o apelo de Sócrates ao "cuidado da alma" que realmente levou o espírito grego a romper caminho em direção à nova forma 
de vida. Se o conceito de vida, do bios (que designa a existência humana, não como um simples processo temporal, mas como uma unidade plástica cheia de sentido, como uma forma consciente de vida) ocupa doravante uma posição de tão grande relevo na filosofia e na ética, é à vida real do próprio Sócrates que, numa parte muito considerável, isso se deve. A sua vida foi uma antecipação do novo bios, baseado integralmente no valor interior do Homem. (Idem, p. 499)

Essa longa, persistente e bem-sucedida trajetória da busca do "valor da individualidade" estará sujeita às vicissitudes históricas. Sua forma e seu conteúdo adaptar-se-ão às condições do tempo e do espaço em que forem produzidos. Tal expressão de maleabilidade é digna de nota, se levado em conta o viés educativo: tempos heróicos exigem a biografia de heróis; tempos românticos exigem que as vidas retratadas exibam romantismo; épocas históricas regidas pelo condão da fé exigem que as biografias sejam hagiografias, retratando a pureza e a retidão de santos. Conforme assinala Madélenat (1984, p. 32), "a história da biografia é então a história de seus recomeços sucessivos, de suas adaptações às novas imagens do homem".

Eis, portanto, uma insuspeitada vocação do gênero biográfico: instrumento de uma antropologia filosófica. Por intermédio das biografias retratos, mais ou menos, fiéis de homens na concretude de suas vidas - será possível, talvez, responder à crucial pergunta que define esse campo especializado de investigação filosófica: Que é o homem? Porém, mais especificamente, do ponto de vista educacional, interessa tomá-las como reflexos das "imagens do homem". E o que significa educação, em sua natureza teleológica, senão a criação de imagens modelares com base nas quais a atividade educativa perseguirá os tipos de homens que se deseja forjar?

Periodizações históricas são sempre problemáticas. Raramente se consegue justificar convincentemente as mudanças de um período para outro. A fluidez dessas "fronteiras" constrange, sobretudo quando fatos e eventos históricos insistem em ser refratários ao enquadramento rígido em uma dada época. É necessário tomá-los mesmo em sua fluidez, única forma de aproveitá-los como exceções que justificam a regra.

O caso das biografias tem um agravante: trata-se da representação de vidas de indivíduos, as quais, em sua singularidade, serão tanto 
efeito quanto causa das transformações ocorridas em sua época histórica. Encontrá-las resistentes ao rígido enquadramento teórico que define as características de um dado período histórico, longe de ser um mal, é um bem, metodologicamente falando - é a prova definitiva do dinamismo, da riqueza e da complexidade das vidas, de sua capacidade de "fazer a história". Mas, por outro lado, negar seu condicionamento ao "espírito do tempo", de que fala Dilthey, implicaria, além de negar o óbvio, tornar impossível o enquadramento das histórias de vida no fluxo mais amplo da história, com seus quadros teóricos, suas amplas periodizações, sua luta, enfim, para escapar do relativismo e do subjetivismo e sair em busca de uma base científica de generalização.

Incapaz de acompanhar e aproveitar toda a riqueza das singularidades, a investigação humana tem de estabelecer parâmetros explicativos. Para fazer isso e, ao mesmo tempo, tentar fugir às periodizações estritas, em sua análise do gênero literário, Madelénat (op. cit.) optou por uma alternativa metodológica: trata-se da adoção da "teoria dos paradigmas", proposta por Thomas Kuhn (1970) em seu estudo clássico sobre a história da ciência.

Segundo a teoria de Kuhn, existem quadros explicativos, correspondentes a períodos mais ou menos longos. Durante tais períodos, imperam os "paradigmas", que são, no sentido amplo, conjuntos de crenças, de valores reconhecidos e de técnicas comuns aos membros de um grupo. No caso da ciência, conforme afirma Kuhn, estabelece-se a "normalidade", que é um esquema ou modelo aceito, a partir do qual tanto as teorias quanto as práticas são estabelecidas, testadas e confirmadas; no qual as soluções de problemas, bem como as regras de observação e interpretação são definidas. As mudanças ("revoluções científicas", como as denominou Kuhn) dependem da superação do paradigma estabelecido. Assim, a análise aristotélica do movimento, o cômputo da posição dos planetas, de Ptolomeu, ou a matematização do campo magnético, levada a efeito por Maxwell, são exemplos de paradigmas, que o tempo, no desenvolvimento da ciência, se encarregou de superar e substituir por outros paradigmas.

Madelénat transporta a teoria dos paradigmas para a história do gênero biográfico. Segundo afirma, é possível identificar paradigmas que, ao longo dessa história, conformam três períodos: o "clássico", o "romântico" e o "moderno". As biografias adquirem certas características do paradigma a que correspondem, fazendo com que os relatos de vidas 
ressaltem este ou aquele aspecto, em que o estilo de narração seja tal ou qual, em que a forma do relato obedeça a determinados padrões, abandonando outros.

Vale ressaltar, aqui, um outro aspecto, não abordado por Madelénat, mas que é crucial para o desenvolvimento da argumentação em favor da instrumentalidade educativa das biografias. Trata-se do fato de que as próprias vidas dos biografados tanto assimilam quanto resistem aos paradigmas, traduzíveis na expectativa da sociedade em relação a seu comportamento. Desse modo, uma vida vivida de forma "iconoclasta" - em relação às regras paradigmáticas estabelecidas ganha interesse biográfico. Vidas vividas na sensaboria da rotina não são biografáveis. Do ponto de vista da instrumentalidade educativa, essas vidas "marcantes", "diferentes" são decisivas: elas é que possibilitarão a construção de modelos de conduta "revolucionários" (para utilizar a terminologia de Kuhn) em face dos modelos estabelecidos pelo paradigma vigente. Por outro lado, vidas podem ser marcantes igualmente na defesa do paradigma estabelecido, o que significa que também são valiosas como instrumentos educativos, para resistir a um modelo educativo, quando este, contrariando a essência transformadora da educação, sua capacidade de dar guarida à renovação representada pelos novos seres que ingressam no mundo, se torna conservador, tradicionalista e resistente às mudanças e inovações.

O primeiro paradigma, denominado por Madélenat "clássico", estende-se da Antigüidade ao século XVIII. O período é longo, e várias são as transformações por que passa o gênero biográfico. Não obstante, algumas características gerais se destacam: o relato - a descrição da vida - suplanta a representação; mas a estilização dos eventos reais é válida, para que o relato biográfico surta os efeitos desejáveis em face de uma instrumentalidade política, moral ou religiosa; mais do que "fidelidade", impõe-se uma retórica, na qual vidas se fundem na "vida exemplar".

Segundo Madelénat (1984, p. 36ss), na Antigüidade greco-latina, a decadência da polis é que leva à necessidade e à possibilidade da biografia: o relato de vidas individuais só se torna importante, relevante, quando sobrevém o desencanto motivado pela deterioração da vida na cidade, da mudança na condição hegemônica de "cidadão", em relação a quaisquer outras condições da vida de cada um. A biografia surge na ruptura havida entre a civilização da pólis e os grandes impérios que se lhes seguem: na crise, impõe-se a necessidade do regis- 
tro, cujo "balizamento" são vidas que se relatam. No século IV, o "elogio" (encomion) marca a distinção entre as virtudes como ideal filosófico e sua manifestação em vidas concretas, as quais, por constituírem essa manifestação, serão dignas de relato.

Roma inaugurará, com Varrão, os "retratos", e, com Cornélius Nepus, as "vidas paralelas", formato comparativo imortalizado posteriormente por Plutarco, e que, segundo Madelénat, "representa o apogeu da biografia antiga numa confrontação simbólica das duas culturas dominantes que dividirão doravante o império..." (1984, p. 42).*

Talvez jamais uma época histórica tenha confiado à biografia um papel tão específico como a Idade Média. O paradigma da expressão do Bem, da reta conduta, o objetivo da edificação predominam. Conforme acentua Madelénat, "o importante não é a continuidade de uma existência humana, mas somente os instantes durante os quais o Bem se objetiva" (idem, ibid., p. 44).

Durante um milênio reinarão as hagiografias: as vidas de santos e as vidas piedosas substituirão as vidas de heróis. A mudança é lenta, progressiva, na marcha das transformações que levarão ao Renascimento. A biografia é uma instância sensitiva, absorvendo essas mudanças, e transformando-se em função das transformações do mundo. Desse modo, permanece um instrumento hábil para o entendimento não somente de um homem, o biografado, mas do Homem, ${ }^{5}$ ser que, pondo-se como eixo e fulcro de tudo, toma em suas mãos o destino do mundo.

O enfraquecimento gradual dos valores medievais, a emergência correlativa do individualismo (com o sentido das virtualidades humanas, da glória terrestre, e, entretanto, o drama da salvação pessoal, intuição fundamental da Reforma), a multiplicação do livro impresso (que oferece ao público burguês o acesso à cultura), a redescoberta da civilização antiga constituem uma mutação favorável à biografia que utiliza modelos greco-latinos para transmitir uma nova imagem do homem. (Madelénat 1984, p. 46)

O Humanismo e a Renascença fazem recrudescer a admiração pelas formas antigas. Não obstante a renovação à qual induzirão, no campo da biografia estabelece-se uma composição com a forma

\footnotetext{
* Todas as citações desta obra foram traduzidas pelo autor.
} 
imperante na Idade Média. Sobre isso, assinala Madelénat: "Nenhuma ruptura, de outra parte, com a hagiografia, que continua abundante e rica em prodígios, mas então um ramo erudito e crítico se aproxima de uma concepção moderna da biografia fundada sobre o documento autêntico" (idem, ibid., p. 45).

Embora fale em "nenhuma ruptura", o próprio Madelénat nos aponta o caminho da mudança de rumos, quando afirma que biógrafos, como Plutarco, traduzidos em francês e latim, entre os séculos XV e XVI,

subtraem a historiografia humanista às rotinas da crônica para consagrá-la à análise dos destinos e das intrigas políticas. Influências misturadas: o espectro de desdobra entre o "caráter", abstrato, e a compilação de anedotas, herança longínqua dos "exemplos" de Cornelius Nepos, contrapartida engraçada da majestosa seriedade da história geral. (Idem, ibid., p. 46)

O gênero se firma como relato com características próprias. A prova é essa sua conotação de "história alternativa" em relação à história em geral, a característica de, pelo riso, impor-se como instância válida, como fonte histórica - uma fonte muito particular, correspondente à narração de uma vida, a qual, no entanto, ilumina o contexto onde é vivida. O jocoso, o risível, o ridículo burlam a vigilância exercida pelo poder e expõem, por meio de vidas individuais caricaturadas, as mazelas de toda a sociedade.

A época moderna, com as conquistas da ciência, contribuirá para lançar cada vez mais o Homem no centro dos acontecimentos. Um homem transformador da natureza, pela ciência, conviverá com um homem que se volta para dentro de si, quando, cético, não confiar mais nos sentidos. Cogito ergo sum. Apenas dentro de si esse homem encontrará a certeza com que procurará construir um mundo de "verdades". Egocentrado, esse indivíduo moderno inventará seu mundo interior, a partir do qual construirá filosoficamente todo o resto. Inventará, também, o mundo da intimidade, desconhecido das épocas anteriores. Esse mundo pessoal e íntimo possibilitará uma visão idealizada do mundo, segundo a ótica da sensibilidade de cada um, da subjetividade.

A Renascença é uma época ilustrativa da utilização educativa da biografia. O passado é expresso em vidas concretas, transformando-se em modelos a serem imitados. Sobre essa utilização, consciente e educativa, nos fala Eliade: 
Certamente, na época da Renascença, procurava-se na história antiga, antes de tudo, os modelos para o comportamento do "homem perfeito". Pode-se dizer que Tito Lívio e Plutarco, ao fornecerem modelos exemplares à vida cívica e moral, desempenharam, na educação das elites européias, o mesmo papel desempenhado pelos mitos nas sociedades tradicionais. ${ }^{6}$

O século XVIII trará profundas alterações no gênero biográfico. É um século em que a individualidade, regida pela ascensão burguesa, firma-se como uma exibição pública das pessoas. Conforme assinala Sennet, a atividade de andar pelas ruas, de mostrar-se, de exibir-se para a sociedade, como forma de firmar a própria identidade, adquire importância. E acrescenta que "o interesse compulsivo na personalidade daquele que se apresenta em público cresceu (...)" (Sennet 1989, p. 347).

A noção de liberdade insinua-se nos meandros da sociedade mediante a crença na expressão plena da individualidade. Mas essa crença necessitava ser projetada no âmbito social para que pudesse efetivar-se. Conforme acentua Sennet (1989, p. 129), "no século XVIII, as pessoas começaram a brincar com a noção de liberdade (...) de tal maneira que o desejo de liberdade se unisse a uma crença na personalidade individual enquanto um princípio social".

O desenvolvimento das atividades econômicas e a concentração urbana do progresso cultural impõem essa exibição, que acentua a necessidade de destacar, registrando-lhes a trajetória, aqueles indivíduos que se sobressaem na difícil tarefa de "aparecer" em sociedade. Isso dá asas à imaginação dos criadores de formas para o relato biográfico: surge a biografia profissional, que também se insere no dicionário histórico, na biobibliografia, no discurso cerimonial, no elogio. Tais formas dramatizam-se e ganham autenticidade quando se aplicam a vidas concretas na forma do relato biográfico.

Há que se destacar, no século XVIII, o surgimento das academias, nas quais o gênero biográfico ganha impulso: os pares integrantes dessas instituições celebram as virtudes dos companheiros biografando-os. E ressalte-se, para o propósito deste artigo, que a biografação vai em busca da exemplaridade, conforme assinala Madelénat (1984, p. 49):

No século XVIII, com o desenvolvimento das academias, o elogio domina a eloquência biográfica; ele tem, de saída, a função de 
celebrar, numa espécie de culto laico, uma corporação por intermédio de um de seus membros dado como exemplo de ciência ou de moralidade; depois se torna uma espécie de dissertação, freqüentemente proposta como tema de concursos promovidos pelas academias. Tais biografias oscilam entre a narração e o discurso retórico.

O próximo paradigma, denominado "romântico", corresponde ao período que vai de fins do século XVIII até o início do século $X X$, por volta da época da Primeira Guerra Mundial.

O paradigma clássico impunha ao gênero biográfico certos padrões, como a medida quantitativa das realizações, divisões estruturais na narrativa e algumas tradições temáticas. Esses padrões são recusados pelo novo paradigma, o romântico, que prefere buscar a representação "verdadeira" de um personagem. Para tanto, a solidez das normas literárias neoclássicas precisa ser quebrada; uma realeza teocrática tem de ceder lugar às aspirações democráticas; os ideais comunitários precisam contrapor-se ao estrito individualismo liberal. Nessas rupturas, assinala Madelénat (1984, pp. 51-52), instala-se o paradigma romântico.

Esse paradigma tem como características acentuadas a busca da intimidade, da sensibilidade, da emoção. Importa descrever uma vida mesmo em seu contexto de alienação e solidão; deve-se descrevê-la como uma unidade, uma individualidade possuidora do que Madelénat denomina "singularidade interior". Enquanto o paradigma clássico baseava-se numa atitude racional, o novo paradigma apóia-se num movimento de base empírica, na concretude variável e instável que contrasta com a "estabilidade" da racionalidade.

O século XVIII introduz mudanças no gênero biográfico que equivalem a uma mudança de mentalidade da sociedade. Na arte narrativa, essa nova mentalidade encarna-se na forma "romance". Tal forma permite tratar as vidas de forma inteiramente diferente, realçando especialmente as nuances de cada personalidade, em contraste com a forma paradigmática anterior, homogeneizadora na busca de "tipos" heróicos que sintetizam as qualidades que a sociedade projeta em seus biografados.

Outra característica: o paradigma romântico permite que a biografia se "popularize", no sentido de ir ao encontro dos indivíduos comuns. Conforme assinala Madelénat (1984, p. 52), "outrora voltado para as aventuras dos grandes, fascinado pela ação vizinha da tragédia, o romance 
adapta-se doravante à representação de um indivíduo médio, próximo do leitor, objeto de compreensão interna".

A história do gênero biográfico começa a ganhar um campo especializado e profissional no final do século XVII, com as biografias de cinco poetas publicadas por Isaac Walton. Baseando-se em documentos, relatos e cartas, esses trabalhos desvencilham-se consideravelmente das construções biográficas anteriores, antes "ilações" que resultado de pesquisa. Walton será o precursor de uma transformação, a ser continuada e aprofundada, por exemplo, por Roger North, que adota um tipo de narrativa inovadora, com a apreciação, por "ângulos" diversos, da diversidade das personalidades. Seu trabalho biográfico sobre seus três irmãos, publicado em 1715 , contém o que se considera "o primeiro ensaio teórico e crítico sobre o gênero, definindo a biografia em sua vinculação com a história, e constrói um ideal de exatidão, de verdade clara e agradável" (idem, ibid., p. 48).

No final do século XVIII é publicada aquela que seria considerada a mais completa, importante e inovadora biografia até então construída: Life of Samuel Johnson, de James Boswell. Johnson, o mais implacável crítico literário de seu tempo, era, ele mesmo, biógrafo. Atingira o profissionalismo biográfico com seu trabalho The lives of the english poets, no qual defendia alguns princípios que, a seu ver, deviam nortear a atividade do biógrafo. Um biógrafo, sustentava, deve dizer a verdade; sua tarefa é descrever, nos mínimos detalhes, o dia-a-dia de uma vida, pois com esses detalhes é que se pode recriar o caráter de alguém em sua trajetória no mundo.

Boswell, seguindo os conselhos do próprio Jonhson, torna-se um implacável acompanhante de seus passos, um observador diligente e meticuloso de todos os seus atos e atitudes, com os quais construirá sua biografia. Pela primeira vez os papéis pessoais e, mesmo, os detalhes da conversação de um personagem servem como matéria-prima para o trabalho do biógrafo. O que consideramos hoje uma técnica moderna, a entrevista com os que conviveram com o biografado, foi usada por Boswell, que teria feito, desse modo, história oral avant la lettre.

A atitude fundamental de Boswell marcaria, doravante, a trajetória do gênero biográfico, pelo menos em sua intenção: apresentar o biografado "como ele realmente é". E essa fidelidade a uma "verdade intrínseca" do biografado será perseguida levando em consideração dois parâmetros fundamentais ditados pelo contexto histórico. O primeiro é a tomada de consciência de que o homem é um "ser social", mostrada tanto pelo desenvolvimento das investigações sociológicas 
quanto pela mobilização da sociedade em favor de direitos sociais básicos; o segundo, a demonstração de que há uma dimensão determinante no ser humano, sem a qual sua reconstrução biográfica será imprecisa e incompleta: a dimensão psíquica. Dois nomes pontificam em correspondência com cada uma dessas dimensões: Marx e Freud. As dimensões social e psicológica tornar-se-ão daí por diante obrigatórias para uma biografia bem construída e digna de respeito do ponto de vista científico.

Ao final desse período paradigmático, a biografia enfrenta oposições que a encurralam sob o argumento de sua "particularidade". Conforme acentua Madelénat (1984, pp. 57-58),

o contexto ideológico é pouco favorável, da "filosofia" resultante das Luzes ao utilitarismo, ao positivismo e ao cientificismo: o parti pris de descobrir as leis sociais, um funcionamento racional e inteligível das atividades humanas exclui a abordagem biográfica, cercada em sua particularidade. Para os filósofos da história que concorrem entre si, e se fundam no progresso do Espírito, da Idéia, no mecanismo das lutas étnicas ou sociais, os homens sofrem ação, mais que agem, e a coletividade é o primum mobile. Daí a marginalização da biografia, infra-história, ou sua tentativa para se elevar à dignidade do grande gênero por um inchaço em "vida e época".

O paradigma impõe a hegemonia das visões positivista e cientificista. A exigência da pesquisa empírica baseada em documentos, a necessidade de provas, a busca de motivos explícitos e fins determinados, enfim, a procura da clareza em lugar da intenção não-expressa dão sinal do esgotamento dessa fase. Não obstante, e por paradoxal que pareça, a produção de biografias cresce. Surgem até bibliografias de biografias! Nas três últimas décadas do século, a biografia penetra nas universidades, sobretudo na França, tornando-se objeto de estudos eruditos, com metodologia positivista.

O homem contemporâneo constrói um mundo no qual é cada vez mais estranho. Um mundo de máquinas, de exatidões, "certezas" e "positividades", que acaba por se mostrar inóspito para seu próprio demiurgo - o Homem - enquanto singularidade, enquanto imprevisibilidade. O marco divisório para um novo paradigma - o paradigma moderno - é a Primeira Guerra Mundial. Essa conflagração global dá a me- 
dida da capacidade humana de produzir a desumanidade em escala planetária. O conflito generalizado atesta a eficiência do homo faber empenhado em construir artefatos de guerra, enquanto exila sua humanitas para a dimensão da utopia.

Essa época corresponde, não por acaso, a uma crise de valores que afeta todas as dimensões da convivência humana. As velhas crenças e doutrinas caem por terra; o homem heróico - personagem central e construtor de sua própria história vitoriosa - cede lugar a um homem complexo, contraditório, manietado por suas perplexidades. Não se crê mais no modelo de homem "monolítico", incólume em relação a desvios em sua trajetória de vida.

A biografia se ressente dessas transformações e se modifica. Está encerrada a carreira vitoriosa, como modelo, das biografias moralistas ou laudatórias e comemorativas. O novo modelo biográfico é a obra de Lytton Strachey, publicada em 1918, Eminent victorians, em cujo prefácio está a defesa de alguns princípios que norteiam a construção biográfica em novos moldes que

condenam as pretensões à exaustividade, os respeitos institucionalizados e as mentiras piedosas (...) Strachey é irônico, leve, hábil em aguçar a curiosidade e manejar os contrastes (...). 0 novo estilo reclama o direito à imaginação, à verdade poética, à reconstrução inventiva, uma vez captada a lógica de uma personalidade. (Madelénat 1984, p. 6)

O novo modelo sofre dupla pressão: por um lado, da "objetividade" e da "isenção" exigidas pela abordagem científica; por outro, da construção ficcional. Biografias transformam-se num instrumento sintomático da publicização da vida. A exposição ao âmbito público é total; e o produto a apresentar exige dos biógrafos a confiabilidade do cientista e a inventividade do artista.

Questões como a do problema metodológico da aproximação e da afinidade entre biógrafo e biografado tornam-se marcantes no paradigma, que hoje continua em vigor. Para muitos, a afinidade é um instrumento fundamental no esforço de reconstrução de uma vida através da biografia; para outros, compromete esse esforço de reconstrução e a mínima objetividade requerida. 
A relação estreita ou a indissociável vinculação entre a vida e a obra versus a defesa da independência entre essas duas instâncias; a maior ou menor liberdade do biógrafo como artista; a predominância que se alterna entre a vida vivida e os documentos que a ela correspondem - eis alguns dos outros tantos problemas enfrentados pela moderna biografia.

O gênero continua consagrando seus cultores. Assim, um Emil Ludwig, ${ }^{7}$ que constrói a trajetória de uma vida apoiando-a no diagnóstico preliminar do temperamento congênito do biografado; um André Maurois, ${ }^{8}$ oscilando entre posições metodológicas menos aventurosas e a liberdade da reconstituição da interioridade de um personagem; um Stefan Zweig, ${ }^{9}$ que combina uma interpretação intuitiva - herança modelar de Saint Beuve ${ }^{10}$ - com uma fidelidade estrita a documentos e peripécias de uma existência.

Nos dias que correm, mais do que nunca, recorre-se ao gênero biográfico. E o momento histórico se afigura muito propício para a construção de biografias. A síntese unificadora representada pela encarnação em uma vida das peripécias acontecidas num mundo complexo nunca pareceu tão adequada como instrumento de investigação histórica. Conforme acentua Madelénat (1984, p. 73),

a crise dos últimos anos, a recusa à massificação, a colocação em questão de ideologias dominantes, a renúncia à total inteligibilidade do real, o conjunto desses fenômenos econômicos, sociais e culturais parece ter formado um clima favorável à biografia (como ao individualismo, ao "novo romance", a um amor nostálgico e ecológico pelo patrimônio).

O mundo moderno cultiva a velocidade como elemento essencial. Tudo muda celeremente. Talvez por isso haja uma preocupação com a idéia de patrimônio, com o sentido da salvaguarda. Conforme afirma Jeudi (1990, p. 12), "impõe-se uma 'etnologia de urgência' relativamente à memória, isto é, obriga ao seu resgate antes que seja tarde".

Essa urgência é verdadeira tanto social quanto pessoalmente. Socialmente, em virtude das mutações aceleradas da vida, que não permitem deixar marcos ou marcas, que exigem o consumo obsessivo, e impedem a fixação de bens patrimoniais culturais, com base nos 
quais grupos culturais estabeleçam seus parâmetros de ação, reconhecimento, pertencimento e identidade. Pessoalmente, essa urgência caracteriza, por exemplo, a vida daqueles indivíduos que, prestes a deixar o mundo pela morte, correm a registrar suas experiências escrevendo memórias ou autobiografias, ou se tornam suscetíveis de relatos, objetos de biografias, assuntos de histórias para os que os sucederem na vida no mundo.

Essa necessidade de "fixação" onde tudo se move transforma-se com uma velocidade impressionante. Onde não há tempo para que o Homem se realize em uma vida, através de seus feitos e palavras, talvez esteja se tornando imprescindível o relato sobre vidas vividas, que só se mostram realmente completas em sua recriação biográfica.

\section{A biografia como instrumento educativo: Oproblema do individual e do coletivo}

Postular a instrumentalidade educativa da biografia coloca-nos em face de alguns problemas, tanto de natureza geral, relativos à biografia em si, quanto específicos, relacionados com sua abordagem na relação com a educação. Neste artigo limitar-nos-emos à abordagem de um desses problemas, qual seja, a questão do individual e do coletivo. Antes do ingresso na apresentação e análise do problema propriamente dito, um esclarecimento se faz necessário, para evitar a criação de um problema suplementar. Trata-se da definição da amplitude com que se está considerando o que seja "educação".

Educação está sendo tomada em seu sentido mais amplo. Não tão amplo, é certo, quanto o queria Stuart Mill, quando afirmou que tudo educa, sendo a Educação

tudo que fazemos por nós mesmos e tudo que os outros procuram fazer com o fim de aproximar-nos da perfeição de nossa natureza. Em sua acepção mais ampla, compreende até os efeitos indiretos produzidos sobre o caráter e as faculdades do homem por coisas e instituições, cujo fim próprio é bem diferente: pelas leis, formas de governos, pelas artes e indústrias ou mesmo por fatos físicos, tais como o clima, o solo, a situação geográfica. (Stuart Mill apud Carneiro Leão 1979, p. 11) 
O sentido amplo aqui invocado corresponde mais ao que concebia Kant, para quem a educação era o desenvolvimento de toda a perfeição de que o indivíduo é capaz; ou ao que defendia William James, ao considerála uma arte adquirida tanto pela intuição quanto pela observação dos fatos e dados da realidade; ou, finalmente, ao que sustentava Herbart, imaginando-a uma ciência que se volta para a formação do indivíduo por si mesmo, despertando nele a multiplicidade de seus interesses (idem, ibid.).

Em suma, a instrumentalidade educativa de que se trata tanto pode estar traduzida na intenção explícita de um biógrafo (a biografia de um educador, por exemplo, dificilmente deixará de ser intencionalmente educativa), quanto na força intrinsecamente educativa do trabaIho biográfico produzido (por exemplo, a biografia de um artista de cinema, televisão, ou a de um desportista, induzindo jovens leitores a comportamentos similares aos desses astros). A perfectibilidade kantiana, a arte definida por James ou a visão científica herbartiana deverão integrar a análise biográfica quando concebida como instrumento educativo.

A biografia trata do individual, da trajetória de uma dada vida, específica, concreta. A educação, por seu turno, embora lidando com cada indivíduo, trata do coletivo: dos conhecimentos, normas, valores etc., com os quais esse ser individual irá participar da vida da sociedade, isto é, da instância coletiva. Do ponto de vista epistemológico, como cuidar da generalização, ou seja, como descobrir a interseção entre a trajetória individual e a da sociedade na qual essa trajetória é percorrida?

Observando a questão de outro ponto de vista: como estabelecer o contorno do individual, isolando-o e, ao mesmo tempo, inserindo-o no coletivo? Do ponto de vista biográfico, como reconhecer o que é comum ao indivíduo e à sua espécie e sua sociedade, em face do que lhe é intrínseco, pessoal, único, original?

Das respostas a essas questões dependerá a validade da biografia como exemplaridade educativa. Afinal, trata-se de utilizar o individual em benefício do coletivo, de fazer com que as experiências, vivências e realizações de um indivíduo sejam apropriadas pela educação, tanto em seu âmbito formal e sistemático - a escola - quanto, especialmente, no sentido educativo mais amplo - a leitura direta da biografia influenciando com os exemplos que contém.

Vale assinalar que preconizarmos a importância da vida vivida por cada indivíduo não significa, em absoluto, ignorar sua condição de "ser no 
mundo", a circunstancialidade, a influência do meio. Não há sequer como imaginar esse indivíduo "isolado", infenso às influências sociais e econômicas, impermeável à historicidade - à sua, pessoal, à da sociedade em que vive e à da História, tomada em seu sentido mais amplo, como o que Ihe atribuiu Hegel ao considerá-la como a realização do Espírito Absoluto.

Recorramos a Dilthey. Sua filosofia determina com precisão a distinção e a integração, aspectos que nos preocupam. Ele crê no que denomina "espírito do tempo" (Geist der Zeit). Em outras palavras: existe uma objetividade no mundo - nas coisas materiais, na concretude dos fenômenos, nas circunstâncias históricas - que condiciona a subjetividade contida no espírito dos homens.

\begin{abstract}
Dilthey amplia o horizonte limitado do historiador. O espírito do tempo atua sobre todos os indivíduos de uma época (...) Toda época oferece uma fisionomia determinada constituída por certos traços gerais aos quais os indivíduos não podem se subtrair, por mais forte que seja sua personalidade; ao contrário, [o espírito do tempo] alcança neles sua mais alta expressão e se exterioriza na obra das grandes personalidades, nas diversas esferas da vida: religião, poesia, música, filosofia, direito, economia, etc. (Pucciarelli 1944, p. 21)*
\end{abstract}

Cada homem concreto, individual é, portanto, o produto dessa simbiose entre sua época, o momento histórico em que vive e sua própria consciência, ou seja, as condições interiores, espirituais, com as quais também convive. O homem é, pois, objetividade do mundo e subjetividade da consciência.

Não se trata de instâncias separadas ou regiões separadas do ser. Consciência e mundo interpenetram-se; de sua interpenetração é que resulta a inteligibilidade. Na consciência é que reside a capacidade de compreensão; o sentido, condição imprescindível para a vida humana e para a vida do mundo - a materialização cultural do homem -, reside na consciência.

Mas o que faz com que cada homem não seja um ser isolado, não esteja condenado a um atroz solipsismo? Somos, em verdade, o

\footnotetext{
* Tradução do autor.
} 
produto de duas percepções: uma interna e outra externa. A percepção interna (espiritual) é responsável pela consciência da mesmidade, da identidade; a percepção externa (material), proveniente das sensações e da percepção do meio, dá realidade ao mundo. Acontece que os homens têm em comum conexões psíquicas; estas é que tornam possível tanto a comunicabilidade entre os seres humanos quanto a construção de um mundo comum que é percebido por cada um e por outrem.

Afirma Dilthey (1945, p. 317):

A conexão adquirida da vida psíquica que encontramos no homem desenvolvido e que abarca ao mesmo tempo imagens, conceitos, determinações de valor, ideais, orientações fixas da vontade, etc., contém conexões constantes que retornam uniformemente em todos os indivíduos humanos e, junto a estas, outras que são próprias de cada um dos sexos, de uma raça, de uma nação, de uma classe, etc., e, finalmente, do indivíduo particular. Como todos os homens se encontram ante o mesmo mundo exterior, desse modo produzem o mesmo sistema numérico, as mesmas relações espaciais, as mesmas relações gramaticais e lógicas. Como vivem nas relações entre este mundo exterior e uma conexão estrutural psíquica que lhes é comum, nascem daqui as mesmas formas de preferir e eleger, as mesmas relações entre fins e meios, certas relações uniformes de valores, certos traços fundamentais do ideal de vida...

A articulação do particular com o geral, do individual com o coletivo dá-se, então, dessa maneira. Para que a articulação aconteça, é necessário comparar as uniformidades encontradas na realidade históricosocial (sistemas culturais, formas de organização, processos de convivência social) com as uniformidades encontradas na vida psíquica.

Há, para Dilthey, duas instâncias integradas porém distintas que delimitam os dois grandes campos do conhecimento: as ciências do espírito e as ciências da natureza. ${ }^{11}$ Nestas, o uniforme, o regular, o representável por leis constitui a meta principal; naquelas, o que se impõe é a particularização, até chegar ao individual. A História encontra sua razão de ser e o sentido mais profundo dos eventos no aprofundamento progressivo no particular. É aqui que se estabelece a relação viva entre o reino do uniforme e o do individual, heterogêneo, particular. 
Conforme acentua Pucciarelli (1944, p. 38):

Enquanto o homem de ciência, preocupado com a busca de leis gerais, considera os objetos individuais como exemplares indiferentes de uma mesma classe, o historiador submerge gostosamente no concreto e no temporal e "nos oferece quadros de homens e vidas humanas com toda a riqueza de suas formas peculiares, com a plenitude de sua vida individual".

Para Dilthey, cada indivíduo é uma unidade de vida espiritual rodeada de circunstâncias. A história de uma vida é a história da representação de suas relações com as circunstâncias físicas e espirituais em que ela se desenvolve. Mas - e isso é o mais importante para efeito da argumentação desenvolvida neste artigo - o sentido se revela nessa unidade vital individual, tanto com base em suas características intrínsecas quanto em suas relações com o mundo. A esse respeito, afirma Dilthey (1945, p. 362) que

o sentido do mundo se revela desde sempre com a maior profundidade nessa individuação, nesta especificação por indivíduos, espécies, gêneros, formas de vida, estruturas típicas e típicas relações. Como disse Goethe, parece que a natureza pôs todo seu interesse na individualidade.

Em relação à importância da trajetória de vida, Dilthey é ainda mais específico: "Na biografia é onde se expressa da maneira mais simples esta valoração independente da pessoa, que é própria das ciências do espírito" (idem, ibid., p. 356).

O homem é um ser profundamente integrado no mundo, mas mantém como ingrediente de sua essência a individualidade. Trata-se de um ser que interage preservando sua forma única, individual, de apropriarse tanto do que se encontra em si, em seu próprio espírito, quanto fora de si. A vivência de um estado próprio e a reprodução de um estado alheio ou da forma de manifestação dessa individualidade de outrem são, para Dilthey, processos similares. Isso possibilita, portanto, que a biografia seja um instrumento eficaz, na medida em que represente uma possibilidade de reproduzir condutas alheias como se fossem originári- 
as da própria vivência interna. Podemos afirmar, então, que a "educação pelo exemplo" inscreve-se nessa constituição do ser no mundo.

Embora reconheça uma dimensão irredutível do individual, Dilthey acentua o caráter histórico dessa manifestação. A arte retrata a dinâmica dessas representações do individual condicionado pela época histórica. As várias dimensões se interpenetram, atuando em complementaridade, de tal modo que "a representação da individuação acha-se condicionada, sempre, de um modo subjetivo e, mais concretamente, de um modo pessoal, nacional e em sucessão histórica" (idem, ibid., p. 374).

Essa interpenetração entre o individual, pessoal, particular, e o coletivo, geral, objetivo, é fundamental tanto para a análise do particular quanto do geral. Os eventos históricos são explicados também pela atuação de grandes homens, de personagens marcantes. Neles, manifesta-se o "espírito do tempo"; é em vidas concretas que se pode captar o sentido de fatos e acontecimentos - da história, enfim.

Porém, indagaríamos, como passar dessas vidas concretas para a generalização exigida pela ciência histórica? Dilthey, usando como exemplo a história da arte, dá-nos a resposta: "Porém, a arte representativa oferece-nos algo mais que reproduções da vida humana. Sua astúcia, para dizer assim, consiste no ver e representar típicos, em oferecer nos fatos a regra do acontecer" (idem, ibid., p. 371).

Eis a passagem: não é cada vida, em si, que interessa à história, mas o que essa vida tem de típica. Existem certas características únicas de cada indivíduo; porém, esse mesmo indivíduo partilha com outros certas características comuns; essas características comuns, por sua vez, representam o "espírito da época" em que a vida é vivida, como os ingredientes devidos a cada cultura.

Vale observar que a biografia, como arte de narrar vidas, embora trabalhe com cada vida em suas particularidades, extrai de cada uma delas certas características típicas. Essa tipologia é que servirá a uma "pedagogia do exemplo". Tomadas como exemplo, imitadas, seguidas, integrando um "modelo" de conduta determinado pelo espírito da época, servirão à educação.

Segundo acentua Dilthey, na arte, a representação da vida se divide entre pessoas e acontecimentos. Podemos acrescentar que uma biografia é a perfeita encarnação de tal combinação. Esse somatório de figuras com circunstâncias reproduz o que denominamos "vida", em suas características essenciais. Acontece que essa combinação não é 
um dado, mas um constructo levado a efeito pelo biógrafo. Aqui, podem ocorrer duas circunstâncias educativas. A primeira é o caso de uma biografia construída com uma intenção educativa; a segunda, quando a ação educativa lança mão da obra, utilizando, para propósitos específicos de formação ou edificação, a narrativa de uma vida originariamente sem aquela intenção.

Dilthey também chega a examinar a circunstancialidade histórica da biografia, quando assinala:

\begin{abstract}
Através desses três grandes séculos, desde o $\mathrm{XV}$ até chegar às primeiras décadas do XVII, vai crescendo constantemente o reconhecimento do valor da individualidade, assim como do direito que assiste à energia, à vontade de poder e às paixões; impõem-se o processo religioso independente no interior da pessoa e o cumprimento religioso ideal de sua esfera de vida; conquistam-se a autonomia do pensamento científico e 0 acabamento da particularidade individual mediante 0 matiz peculiar dos pensamentos. (Idem, ibid., p. 379)
\end{abstract}

Dilthey destaca, ainda, que, nos séculos XVII e XVIII, o universo se acha determinado por leis físicas. O indivíduo é condicionado por seu meio, que tem base histórico-natural. Trata-se, pois, de investigar a história evolutiva do homem dentro de seu meio. A forma artística "biografia" trata exatamente da exposição sobre como se desenvolve um personagem em um meio tanto físico quanto histórico-social. O romance histórico, outra forma de relato desenvolvida na mesma época, busca expor a conexão das condições históricas com os caracteres e destinos individuais.

Para Dilthey, a questão da individuação, incorporada ao método científico, é obra do século XVIII. Essa questão da diferença individual, já tratada na Índia por sacerdotes e em toda a Antigüidade, especialmente pelos gregos, transforma-se num recurso da ciência natural: para estabelecer diferenças, igualdades e gradações é necessário tomar características individuais. E é na biologia onde o método comparativo mais se aplica e se desenvolve.

Há dois suportes fundamentais para o desenvolvimento do pensamento de Dilthey: a historicidade, já mencionada acima, ${ }^{12}$ e a dimensão psicológica. Dilthey intenta uma reinterpretação radical da 
psicologia, substituindo a até então incontestada psicologia explicativa por uma psicologia descritiva e analítica. A base das ciências do espírito será a dimensão psicológica do ser humano, mas não segundo as concepções naturalistas vigentes, com um modelo explicativo baseado em hipóteses fundadas na manifestação de fenômenos separados, em elementos "atomizados", na expressão de Dilthey (1945, p. 227). Assim, a causalidade estabelecida entre fenômenos psicológicos observados segundo o método científico adotado pelas ciências da natureza é apenas hipotética, não se constituindo na base sólida buscada por Dilthey para servir de alicerce seguro para as ciências do espírito. Essa base será encontrada na consciência mesma, e em sua integralidade, numa essencialidade psíquica oriunda da vivência mesma. Afirma Dilthey (1945, p. 228):

Assim resulta que nas ciências da natureza se nos oferece a conexão natural somente através de conclusões suplementares, por meio de um conjunto de hipóteses. Nas ciências do espírito, pelo contrário, temos como base a conexão da vida anímica como algo originalmente dado (...). Porque na experiência interna se nos dão também os processos de causação, dos enlaces das funções, como membros especiais da vida psíquica, num todo. A conexão vivida é o primário, e o secundário é a distinção dos diversos membros da mesma.

Em última análise, o elemento essencial é, para Dilthey, a vida mesma. A vida se expressa numa totalidade anímica. Em cada indivíduo ela é única, íntegra, embora se complemente em sua vida de relação com o mundo e com os outros seres humanos. A vida é a base firme que buscava Dilthey para fundar a ciência do espírito. Longe da especulação pura, do conceito distanciado da realidade, de uma "razão pura" kantiana, importa considerar a vida mesma, em sua concretude, em sua manifestação. Segundo Carneiro Leão (1977, p. 32), Dilthey

nega a qualquer reflexão conceitual a capacidade de fundar um conhecimento seguro e universalmente válido no domínio da existência. Numa discussão com Hegel e Kant estabelece a vida, valor inconcusso, e a história, a expressão autêntica da vida, o fundamento de toda filosofia verdadeira, por serem as únicas instâncias capazes de dar às investigações do filósofo a segurança e a universalidade. 
A vida, embora determinada pela historicidade, expressa-se de forma original e única em cada indivíduo. Essa expressão configura-se na personalidade. Filloux acentua que a personalidade "é a configuração única assumida no decurso da história de um indivíduo pelo conjunto de sistemas responsáveis por seu comportamento"(Filloux 1960, p. 13). Onde se cruzam e se oferecem ao exame essa "configuração única" e a generalidade histórica encarnada nos fatos históricos "objetivos", isto é, partilhados pelo conjunto dos indivíduos, senão na biografia, que narra tanto a manifestação particular de um indivíduo quanto sua inserção em seu tempo, na realidade histórica do mundo concreto em que vive?

Há que se distinguir a "personalidade" do "personagem". Tal distinção é elementar para que se possa qualificar a biografia como instrumento de análise histórica do entendimento do mundo e não apenas como narração dos fatos ocorridos numa vida. Conforme acentua Filloux (1960, p. 12), o "personagem" é a aparência que uma pessoa se atribui "ao assumir uma personalidade". A biografia, em busca da essência da exemplaridade educativa, que é histórica, posto que se tratada de um recurso de educação utilizado por uma dada sociedade num determinado momento histórico, precisa transcender essa dimensão de aparência e seguir em busca da personalidade, que é mais ampla e mais profunda. Tais complexidade e profundidade apresentam-se em múltiplas dimensões, as quais necessitam ser consideradas, para evitar as armadilhas tanto de um reducionismo individualista quanto de uma imersão coletivista diluidora de qualquer expressão individual. Caracterizando o complexo fenômeno da personalidade, afirma Filloux (1960, p. 12):

Em síntese, a personalidade não é "estímulo social", nem personagem, nem ficção diretriz, nem entidade metafísica. Para se chegar a uma definição formal, que não esteja por demais diretamente ligada a um sistema, o melhor é reportarmo-nos às diversas características que um conceito compreensivo deve correlacionar. 1) A personalidade é única, própria a um indivíduo, embora este possua traços em comum com os outros; 2) Ela não é somente uma soma, um total de funções, mas também uma organização, uma integração; mesmo que essa integração nem sempre chegue a ser realizada é, pelo menos, essa tendência integrativa que define tal noção de centro organizador; 3) A personalidade é temporal, visto sempre pertencer a um indivíduo que vive historicamen- 
te; 4) Por fim, não sendo nem estímulo nem resposta, ela se apresenta como uma variável intermediária, afirmando-se como um estilo através e por meio do comportamento. (grifos do autor)

Tendo em conta essa caracterização de Filloux, vale destacar: personalizar é expressar uma apropriação particular do mundo, é integrar de uma certa maneira dados que são oferecidos pela realidade do mundo. Isso tem uma implicação interessante que nos aproxima do problema analisado aqui. A educação é uma forma de promover essa integração dos fatos e dados existentes no mundo de uma determinada forma, definida pela sociedade. Em outras palavras, ser "educado" é, na dimensão coletiva, aprender a ser e reagir de determinadas maneiras que servem ao meio social. Ora, estudar a vida de alguém, e fazer dessa vida um repositório de exemplos educativos, é selecionar as reações desse alguém diante da vida, e tomar tais reações como modelos para aqueles que se busca educar. Exemplos "positivos", ou exemplos "negativos", obviamente, quando se trata de ensinar pela contraposição.

Mas, como vimos em Dilthey, a vida de cada um não é redutível ao coletivo; ela resiste, por ser original e única, e nessa resistência está a origem do novo, do que virá servir de base para a mudança, para a transformação. A biografia, relato de uma vida concreta, está no entrecruzamento do individual e do coletivo, podendo expressar, dessa forma, tanto a inovação quanto a afirmação, e estas não propostas idealmente, mas manifestadas realmente, mostradas como são, tornadas factíveis e possíveis.

Se o relato dessas vidas é distorcido a ponto de mostrar um homem real, concreto, falível e contraditório como um ser ideal, heróico, modelar e sem mácula, isso é tema para outras reflexões dentre as inúmeras em que se pode desdobrar o problema de tomar a biografia em sua instrumentalidade educativa.

\section{À guisa de conclusão}

A importância da biografia pode ser suficientemente demonstrada. Sua impressionante resistência ao longo dos séculos, como gênero literário e como fonte historiográfica, é prova disso. Sua adaptabili- 
dade aos momentos históricos demonstra sua utilidade como instrumento de compreensão do mundo humano e dos seres que os integram os indivíduos. São estes, como seres concretos, únicos, insubstituíveis, impermutáveis, que garantem a "verdade" das teorias e a veracidade das interpretações. Neles - e não nas generalizações, abstrações e teorias - pulsa a vida de que fala Dilthey. A eles cabe a resistência às homogeneizações: são os guardiões da heterogeneidade e, como conseqüência, da originalidade, da irrupção do "novo", única forma de fazer com que a educação sirva à sociedade, impedindo-a de sucumbir na mesmice da preservação do status quo ou na armadilha de um conservadorismo empedernido.

A importância específica da biografia como instrumento educativo parece óbvia, pois é nos exemplos de vivências humanas reais que a educação vai buscar os modelos com os quais procura forjar a imagem de homem a ser formado pela educação. Porém, filosoficamente falando, o óbvio não pode ser ponto de chegada, mas de partida. Além de constatar a instrumentalidade educativa explícita na maioria das biografias, é necessário ir além, procurando desvendar as motivações por detrás dessa utilização dos relatos de vida. É preciso resgatar a importância da individuação, porém, sem a ingenuidade isolacionista. O cruzamento entre a apropriação individual do mundo e a recorrência das conexões comuns à coletividade humana é o locus da inteligibilidade acerca da relação entre o uno e o múltiplo, entre o ser individual e o ser social.

A educação, na qual sempre se estabelece uma tensão entre a heterogeneidade do individual e a homogeneidade do social, tem nas biografias um instrumento valioso - único, aliás, que se presta ao teste de suas teorias na experiência insubstituível e insuperável da vida concreta -, além de constituir-se num manancial inesgotável para as exemplificações. Por isso, torna-se relevante estudar a biografia em sua instrumentalidade educativa.

\section{Notas}

1. Lembremos Sócrates, no Mênon, indagando se a virtude é transmissível. Ao contrário das habilidades, as virtudes necessitam ser vivenciadas, praticadas efetivamente na vida e mostradas por atos e palavras. Nada garante que a virtude foi assimilada senão a observação, feita por outrem, sobre a trajetó- 
ria da vida. E a apropriação da virtude (ou de qualquer bem moral) acaba por ser feita de forma particular, única, intransferível, segundo a vida de cada um. Como aprendemos no Mênon, somente o exemplo de uma vida virtuosa serve à propagação da virtude. E qual o instrumento para o relato dessas "vidas virtuosas" senão as biografias? Platão. Obras Completas. Buenos Aires: Anaconda, 1946, vol. 2, pp. 201-250: Mênon.

2. "Jamais defrontaremos com o homem em geral, mas sempre com um homem particular, um indivíduo, que freqüentemente constitui um enigma, um problema cuja solução, bem sabemos, só pode ser encontrada nele mesmo. A característica mais essencial do homem apresenta-se então como sendo a sua individualidade, o fato de ser ele o resultado único em seu gênero e de, separado espacialmente de todos os demais homens, não se assemelhar totalmente a nenhum, comportando-se da maneira que lhe é própria" (Filloux 1959, p. 8).

3. Tese defendida em julho de 1996, intitulada "A biografia e a exemplaridade educativa".

4. Muitos exemplos poderiam ser citados, entre eles o clássico e monumental Um estadista do Império, obra editada entre 1898 e 1899, em que Joaquim Nabuco narra a vida de seu pai, o senador Nabuco de Araújo, obra de consulta obrigatória pelo fidedigno painel que traça de uma fase da vida política brasileira. Outro exemplo marcante e referencial, de outra época e de outro campo, é a obra Machado de Assis, de Lúcia Miguel Pereira, a qual, lançada em 1936, continua insuperável e obrigatória para o estudo de nosso mais genial escritor. E, apenas para fechar estas citações escolhidas ao acaso, o livro de R. Magalhães Júnior, Rui, o homem e o mito (1962), que se mantém como um incólume referencial, a despeito das outras centenas de obras existentes sobre nosso magno jurista, ainda lembrado como "a Águia de Haia".

5. Por causa do exemplo de épocas históricas como essa é que ousei afirmar, no início deste trabalho, que a biografia pode constituir-se num instrumento da antropologia filosófica.

6. Eliade 1972, p. 101: "Mitologia da memória e do esquecimento", p. 120.

7. Escritor alemão e biógrafo de sucesso (1881/1948). Especializado em biografias de grandes figuras históricas, preocupou-se em humanizá-las, conferindo a elas o tom de romance, o que fez com que seus trabalhos caíssem no gosto do grande público. Escreveu muitas biografias entre as quais se contam as de Napoleão, Goethe e Guilherme II.

8. Biógrafo, crítico literário e historiador francês (1885/1967). Construiu biografias romanceadas e imaginativas, de grande sucesso. Entre seus trabalhos mais notáveis estão as biografias de Shelley, George Sand e dos Dumas, pai e filho.

9. Escritor austríaco (1881/1942). Notabilizou-se como biógrafo. Seus trabalhos biográficos são agradáveis de ler como novelas. Exilou-se no Brasil, fugindo do nazismo. Radicou-se em Petrópolis, onde se suicidou. 
10. Escritor e crítico literário francês (1804/1869). Em 1828, escreveu os famosos "retratos literários", perfis biográficos de escritores em que a narração de suas vidas é combinada com análises e apreciações literárias.

11. "Resumindo: a diferença de conteúdos, que serve de base à divisão das ciências, está enlaçada na diferença gnosiológica, ou seja, no modo como nos são dados os objetos: as coisas se nos oferecem como fenômenos quando nos são dadas na percepção externa, ou como realidade quando se dão imediatamente na percepção íntima. Num caso, integram o sistema da natureza; no outro, se adscrevem ao espírito. A natureza se explica, o espírito se compreende. Os conhecimentos se separam assim em ciências da natureza e ciências do espírito." (Pucciarelli 1944, p. 45)

12. Interpretando o pensamento de Dilthey, Pucciarelli (op. cit., p. 23) registra: "Nossa consciência é consciência histórica, porque a historicidade é a essência do homem."

\section{The biography and its educational instrumentality.}

ABSTRACT: The present article treats biography associating it to education through a pretext: that biographic constructions have an educational tool, the example can be appreciated on the context as pedagogic. An integrative part of the author studies culminate in a doctorate thesis at UFRJ, the work shows a historical synthesis of Ethe biographic trajectory such as the periodicity proposed by Daniel Madelénat, besides that it shows a theoretical basis of the biographic analysis specially based on Wilhelm Dilthey. The article also points out the importance of working the biography and studying its relation with the education.

\section{Bibliografia}

CARNEIRO LEÃO, Emmanuel. Aprendendo a pensar. $2^{a}$ ed. Petrópolis: Vozes, 1977.

. "A viagem da educação". Revista Brasileira de Estudos Pedagógicos. Brasília, vol. 63, nº 144, p. 11, maio/ago. 1979.

DILTHEY, Wilhelm. Psicología y teoría del conocimiento. México: Fondo de Cultura Económica, 1945.

ELIADE, Mircea. Mito e realidade. São Paulo: Perspectiva, 1972.

FILLOUX, Jean-C. La personnalité. Paris: PUF, 1959. 
. A personalidade. São Paulo: Difusão Européia do Livro, 1960.

JAEGER, Werner. Paideia - A formação do homem grego. São Paulo: Martins Fontes, 1979.

JEUDY, Henri-Pierre. Memórias do social. Rio de Janeiro: Forense-Universitária, 1990.

KUHN, Thomas S. The structure of scientific revolutions. $2^{\mathrm{a}}$ ed. Chicago: The University of Chicago Press, 1970.

MADÉLENAT, Daniel. La biographie. Paris: PUF, 1984.

PUCCIARELLI, Eugenio. "Introducción a la filosofía de Dilthey". In: DILTHEY, Ghillermo. La esencia de la filosofía. Buenos Aires: Losada, 1944.

SENNET, Richard. O declínio do homem público. São Paulo: Companhia das Letras, 1989. 